\title{
Inhibition of gastric secretion and motility by simulated upper gastrointestinal haemorrhage: a response to facilitate haemostasis?
}

\author{
G M FULLARTON, E J S BOYD, G P CREAN, K BUCHANAN, \\ AND K E L MCCOLL
}

From the University Department of Medicine and Surgery, Western Infirmary, Glasgow and Gastrointestinal Centre, Southern General Hospital, Glasgow and University Department of Medicine, Queen's University, Belfast

SUMMARY As gastric acid and pepsin inhibit blood coagulation and platelet aggregation it is surprising that most upper GI haemorrhages stop spontaneously. To investigate this paradox we have studied acid and pepsin secretion, gastric motility and GI hormones after simulated upper GI haemorrhage. In seven healthy volunteers intraduodenal infusion of $160 \mathrm{ml}$ autologous blood decreased pentagastrin stimulated submaximal acid secretion (mmol/h) from 30.0 (3.2) (mean (SE)) in the hour preceding infusion to $21.4(3.7)$ in the hour following infusion $(p<0.02)$, representing a mean reduction in acid output of $30 \%$. Pepsin output $(\mathrm{mg} / \mathrm{h})$ was also decreased from $207 \cdot 5(67 \cdot 7)$ (mean (SE)) in the hour preceding blood infusion to 135.7 (54.7) in the hour after infusion $(\mathbf{p}<0.02)$ representing a mean reduction in pepsin output of $43 \%$. In six volunteers gastric emptying of a liquid meal was delayed after intraduodenal blood infusion compared with intubation alone with the emptying time (min) to half volume $\left(t^{1 / 2}\right)$ being prolonged at $75.0(8 \cdot 2)$ (mean (SE)) after blood infusion compared with $35.5(6 \cdot 6)$ after intubation alone $(p<0.02)$. Plasma GIP concentrations (ng/l) increased to peak levels of $127.9(62 \cdot 7)$ (mean (SE)) after intraduodenal blood infusion compared with the pre-infusion value of $58 \cdot 3(2 \cdot 3)(p<0 \cdot 02)$. These changes may represent protective physiological responses to facilitate haemostasis.

Considering the adverse environment for haemostasis, it is surprising that approximately $80 \%$ of acute upper GI bleeds stop spontaneously. The resting $\mathrm{pH}$ of the stomach and proximal duodenum is usually less than 2 and platelet aggregation and plasma coagulation are abolished in vitro at $\mathrm{pH}$ values of $<5 \cdot 4$.' $^{\prime}$ astric juice is also rich in pepsin, a potent fibrinolytic agent which rapidly digests thrombus in acid medium of $\mathrm{pH}<4 .{ }^{23}$ The fact that haemostasis is usually effective in the upper GI tract suggests the presence of specialised physiological

Address for correspondence: Dr Kenneth E L McColl, University Department of Medicine, Western Infirmary, Glasgow G11 6NT.

Accepted for publication 28 July 1988. mechanisms to facilitate haemostasis in this unusual environment. In order to determine whether such mechanisms exist we have studied the effect of simulated upper GI haemorrhage on gastric acid and pepsin secretion, gastric motility and GI hormone release.

\section{Methods}

\section{GASTRIC SECRETION STUDY}

The effect of simulated intraduodenal haemorrhage on gastric acid and pepsin secretion was studied in seven healthy volunteers (six men, one woman, median age 29 years, range $25-36$ ). After an overnight $(12 \mathrm{~h}$ ) fast, a size 8 duodenal tube (Viomedex) 
and size 14 vented Andersen gastric tube (AN 10, HW Andersen Inc, New York, USA) were passed under fluoroscopic control into the second part of the duodenum and body of stomach respectively. This allowed simultaneous intraduodenal infusion and gastric aspiration without contamination. At time zero, an iv infusion of pentagastrin (Peptavlon, ICI) $0.25 \mu \mathrm{g} / \mathrm{kg} / \mathrm{h}$ was commenced and continued throughout the study to stimulate submaximal gastric secretion. After a 30 minute equilibration period, $4 \times 15$ min collections of gastric juice were obtained by continuous aspiration. After this (time 90 minutes) each volunteer was blindfolded and received intraduodenally either $160 \mathrm{ml}$ of fresh, unclotted autologous venous blood or $160 \mathrm{ml}$ egg white (which has a similar protein and carbohydrate content to blood). Intraduodenal infusions were administered in random order on separate days at least one week apart. Infusions were given as $4 \times 40$ $\mathrm{ml}$ aliquots at five minute intervals over 20 minutes. On each study day $40 \mathrm{ml}$ of venous blood was removed from each volunteer's arm every five minutes for 15 minutes (total volume removed $=160$ $\mathrm{ml}$ ) and either directly infused into the duodenum before clotting (blood study day) or discarded (egg study day). After the start of duodenal infusion, a further $4 \times 15$ min gastric collections were taken ( 90 $150 \mathrm{~min}$ ). Volumes of each $15 \mathrm{~min}$ gastric aspirate were measured and aliquots retained for assay. A summary of this study method is shown in Figure 1.

Corrections were made for pyloroduodenal loss by infusing a non-absorbable marker, phenol red solution $(1500 \mathrm{mg} / \mathrm{l})$ at $12 \mathrm{ml} / \mathrm{h}$ intragastrically throughout the study. ${ }^{4}$ Corrections for duodenogastric reflux of duodenal juice were made by estimating $\mathrm{Na}^{+}$concentration of the gastric aspirate. ${ }^{5}$ Microscopic blood reflux was quantitated spectrophotometrically. ${ }^{6}$ Any study showing macroscopic reflux of blood or egg white was abandoned. Macroscopic egg white reflux was detected visually by its effect on phenol red in the aspirated gastric juice, turning the normal acidic yellow/orange colour to pink. Four studies were repeated because of macroscopic reflux of blood in three, and egg white reflux in one.

\section{GASTRIC MOTILITY STUDY}

The effect of simulated intraduodenal haemorrhage on gastric emptying of a $600 \mathrm{ml}$ liquid glucose meal was studied in six healthy volunteers (five men, one woman, median age 29 years, range 25-36) using a double sampling test meal technique. ${ }^{7}$

After an overnight fast, separate intraduodenal and gastric tubes were positioned as described above. At time zero $600 \mathrm{ml}$ of a liquid meal $(50 \mathrm{~g}$ dextrose diluted to $600 \mathrm{ml}$ in $75 \mathrm{mmol} / \mathrm{l} \mathrm{NaCl}$ with phenol red

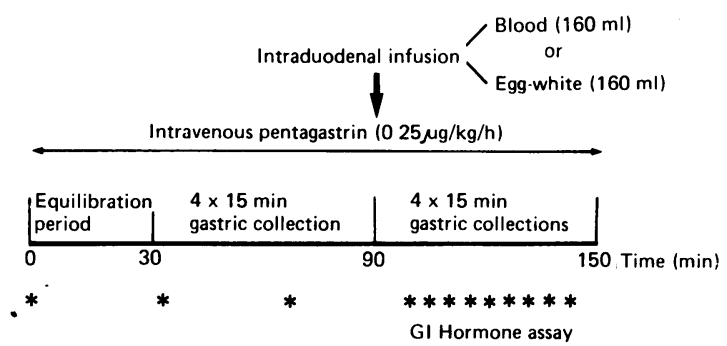

Fig. 1 Experimental study method to determine effects of intraduodenal blood and egg white infusion on pentagastrin stimulated gastric secretion.

solution $45 \mathrm{mg} / \mathrm{l}$ ) was instilled into the stomach, mixed and $5 \mathrm{ml}$ aspirate kept for analysis. Each volunteer was then blindfolded and received intraduodenally either $160 \mathrm{ml}$ fresh autologous venous blood $(4 \times 40 \mathrm{ml}$ aliquots over five minute intervals as described above $), 160 \mathrm{ml}$ egg white $(4 \times 40 \mathrm{ml}$ aliquots $)$ or intraduodenal intubation alone in random order on separate days. At 10 minutes, a $10 \mathrm{ml}$ gastric aspirate was removed and kept for analysis. Immediately, $10 \mathrm{ml}$ phenol red solution $(1500 \mathrm{mg} / \mathrm{l})$ was instilled into the stomach, the gastric contents mixed and a further $10 \mathrm{ml}$ gastric aliquot kept for analysis. This double sampling technique was repeated at 10 minute intervals until time 50 minutes when the stomach was emptied completely, the volume recorded and a $10 \mathrm{ml}$ aliquot retained for analysis. The stomach was then washed with $100 \mathrm{ml}$ water which was aspirated, the volume noted and a $10 \mathrm{ml}$ aliquot also retained for analysis.

GASTROINTESTINAL (GI) HORMONE STUDIES

To study possible hormonal mediation of any responses shown, serial blood samples were taken before and after intraduodenal blood and egg white infusion during the gastric secretory study.

Three basal samples were taken at 30 minute intervals before intraduodenal infusion and thereafter at seven minute intervals until study completion at 150 minutes. Samples were added to heparinised tubes, immediately centrifuged and plasma stored at $-20^{\circ} \mathrm{C}$. The following GI hormones with known gastric secretory and/or motility effects were studied - gastrin, secretin, gastric inhibitory peptide (GIP), vasoactive intestinal peptide (VIP), neurotensin and somatostatin.

ANALYSIS

Gastric secretion

Gastric juice was analysed for: (1) Hydrogen ion concentration by titration to $\mathrm{pH} 7.0$ with $100 \mathrm{mmol} / \mathrm{l}$ sodium hydroxide. (2) Phenol red concentration by 
spectrophotometric absorption (Pye Unicam SP8-100 UV Spectrophotometer) at 550 and $410 \mathrm{~nm}$ and at $410 \mathrm{~nm}$ alone to quantitate microscopic blood reflux. (3) Sodium concentration by flame photometry (EEL Flame Photometers Ltd). (4) Pepsin concentration by Pipers method. ${ }^{8}$ Results were expressed as mg Sigma porcine pepsin.

\section{GI HORMONES}

Gastric inhibitory peptide, gastrin, secretin, somatostatin, VIP, and neurotensin were measured by radioimmunoassay.

\section{CALCULATIONS}

Acid output was expressed as total acid output in $\mathrm{mmol} / \mathrm{h}$ for each hour before and each hour after duodenal infusions after correction of pyloroduodenal losses and duodenogastric reflux. Pepsin output was expressed as the total output in milligrams for each hour before and after intraduodenal infusions.

Intragastric volumes were calculated using the method of George. ${ }^{7}$ The time taken for intragastric volume to decrease to half volume from $600 \mathrm{ml}\left(\mathrm{t}^{1} / 2\right)$ was calculated in each case using linear transformation of the data.

For each GI hormone assay preinfusion values were expressed as the mean of the three samples at 0,30 and 60 minutes.

STATISTICAL ANALYSIS

Results are given as mean (SE). Statistical analysis was performed using the Wilcoxon's signed-ranks test (two sided) for paired data. Results were considered significant when $\mathrm{p}<0.05$.

Written, fully informed, consent was obtained in each case and all studies were approved by the Local Hospital Ethical Committee.

\section{Results}

\section{GASTRIC SECRETION}

\section{Acid output}

Gastric acid output ( $\mathrm{mmol} / \mathrm{h})$ decreased in each of the seven volunteers after intraduodenal blood infusion. The mean output being $30.0(3.2)$ in the hour preceding intraduodenal blood infusion and $21.4(3.7)$ in the hour after infusion $(p<0.02)$ (Fig. 2$)$. This represented a mean reduction in acid output of $30.4 \%$ (range $16-67 \%$ ) and was accounted for by a reduction in both the volume and $\mathrm{H}^{+}$concentration of the gastric juice.

With intraduodenal egg white infusion there was no significant change in acid output being $31 \cdot 8(2 \cdot 8)$ in the hour before infusion and $33.0(4.4)$ in the hour after intraduodenal infusion (Fig. 2).

\section{Pepsin output}

Pepsin output $(\mathrm{mg} / \mathrm{h})$ decreased in each of the seven volunteers after intraduodenal blood infusion (Fig. 3 ). The mean output being $207.5(67 \cdot 7)$ in the hour preceding intraduodenal blood infusion and 135.7 $(54.7)$ in the hour after infusion $(p<0 \cdot 02)$. This represented a mean reduction in pepsin output of $43 \%$ (range $19-80 \%$ ) and was accounted for by a

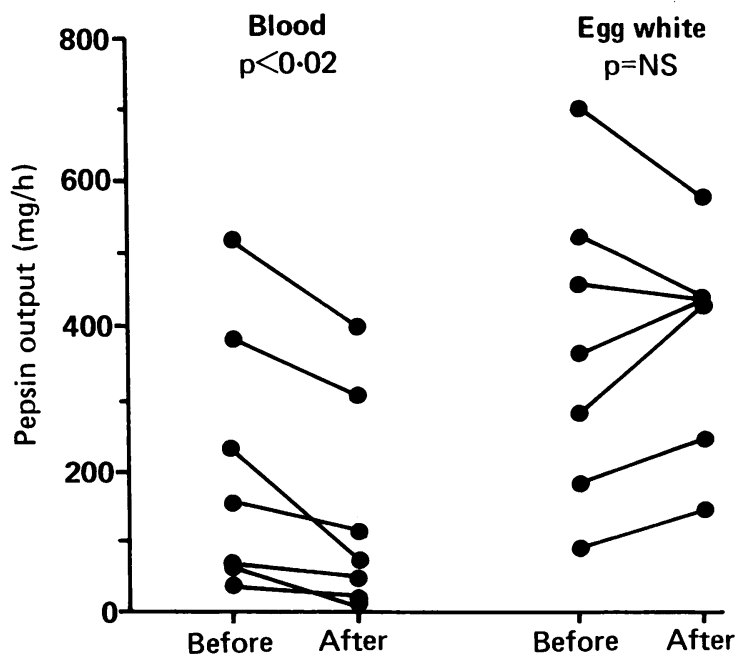

Fig. 3 Effect of intraduodenal blood and egg white infusion
Fig. 2 Effect of intraduodenal blood and egg white infusion on pentagastrin stimulated gastric acid secretion in seven healthy volunteers. on pepsin secretion in seven healthy volunteers.

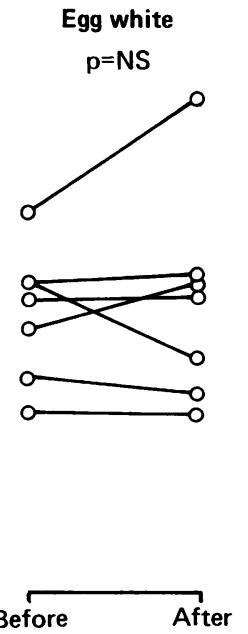




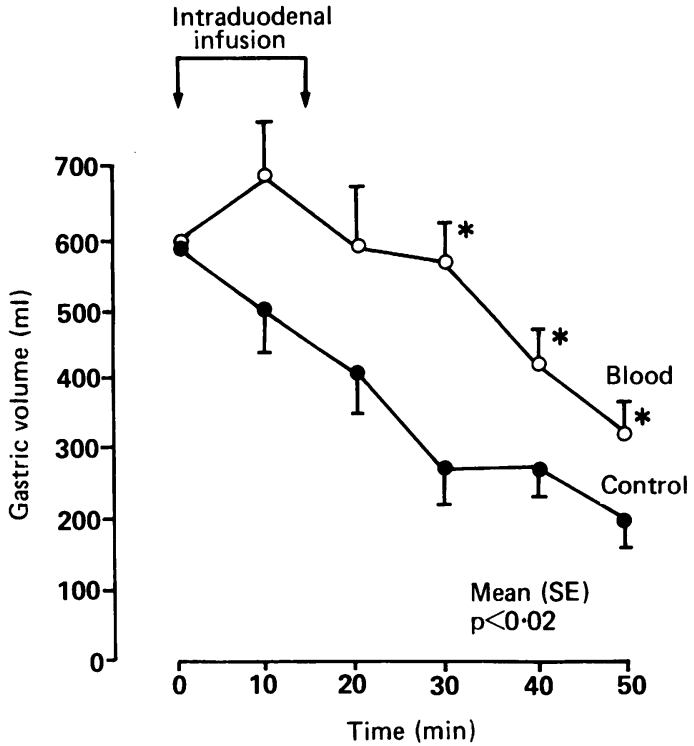

Fig. 4 Residual gastric volumes after intraduodenal blood infusion and duodenal intubation alone in six healthy volunteers. Values are given as mean (SEM).

reduction in both volume and pepsin concentration of the gastric juice. With intraduodenal egg white infusion, there was no significant change in pepsin output being $372.2(82.9)$ in the preinfusion hour and $376.9(54.6)$ in the hour after intraduodenal infusion (Fig. 3).

Calculated recovery fractions by phenol red estimation were $91 \%$ in the blood infusion group and $94 \%$ in the egg white infusion group. The calculated mean volume of blood refluxed in the hour after intraduodenal blood infusion was $3 \cdot 2(0 \cdot 9) \mathrm{ml}$.

\section{GASTRIC MOTILITY STUDY}

Gastric emptying was delayed in all six subjects after intraduodenal blood infusion compared with intubation alone. Figure 4 shows the residual gastric volumes with intraduodenal blood infusion compared with the control study (duodenal intubation alone). The emptying time ( $\mathrm{min})$ for the initial intragastric volume $(600 \mathrm{ml})$ to decrease to half volume $\left(\mathrm{t}^{1 / 2}\right)$ was increased to $75.0(8.2)$ after intraduodenal blood infusion compared with $35.5(6 \cdot 6)$ in the control study $(\mathrm{p}<0.02)$. At 50 minutes, 355 (18) $\mathrm{ml}$ remained in the stomach, compared with 211 (28) $\mathrm{ml}$ after the control study $(\mathrm{p}<0 \cdot 02)$.

Compared with intubation alone, intraduodenal egg white infusion also resulted in a delay in gastric emptying although this was less marked than after blood infusion. $t^{1 / 2}(\mathrm{~min})$ after egg white infusion was

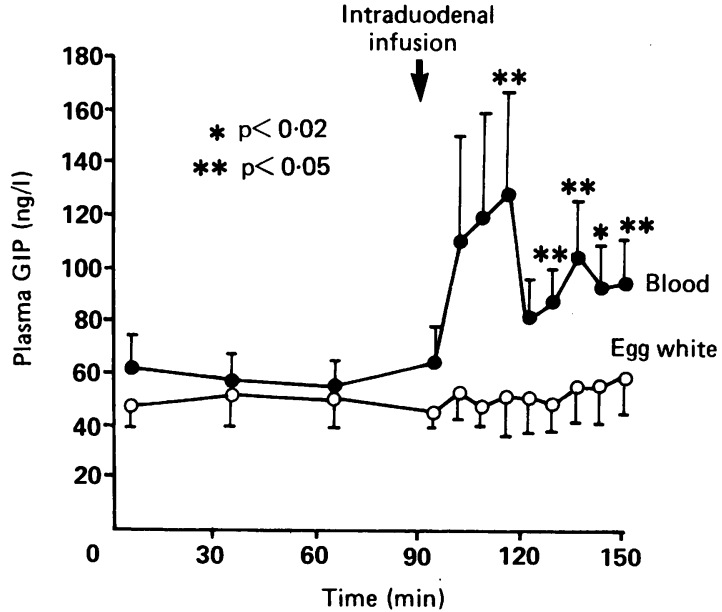

Fig. 5 Venous plasma concentrations of GIP before and after intraduodenal infusions of blood and egg white in seven healthy volunteers. Values are given as mean (SEM).

$67.7(12 \cdot 7)$ compared with control study $35.5(6.6)$ $(\mathrm{p}=\mathrm{NS})$. After egg white infusion 291 (36) ml remained in stomach at 50 minutes compared with 211 (28) $\mathrm{ml}$ after the control study ( $\mathrm{p}=\mathrm{NS}$ ).

\section{GI HORMONES}

\section{Intraduodenal blood infusion}

Plasma GIP concentrations (ng/l) increased significantly after blood infusion compared with preinfusion values $(p<0.02)$ (Fig. 5). Peak GIP levels were reached 21 minutes after the start of blood infusions being $127.9(62.7)$ compared with the preinfusion value of $58.3(2.3)(\mathrm{p}<0.02)$. Gastric inhibitory peptide concentrations remained significantly raised above preinfusion values at the end of the study 56 minutes after the start of blood infusions.

Plasma concentrations of gastrin, somatostatin, VIP, secretin, and neurotensin showed no significant change after blood infusion compared with preinfusion values.

\section{Intraduodenal egg white infusion}

None of the plasma concentrations of hormones studied changed significantly after egg white infusion (Fig. 5).

\section{Discussion}

This study has shown that intraduodenal blood infusion in man inhibits pentagastrin stimulated gastric acid and pepsin secretion, delays gastric emptying and increases plasma GIP concentrations. 
These responses may represent a locally protective physiological mechanism to facilitate haemostasis.

The normal environment of the upper GI tract is not conducive to haemostasis. The resting $\mathrm{pH}$ of the stomach and proximal duodenum is usually less than $2^{910}$ and platelet aggregation and plasma coagulation are abolished at $\mathrm{pH}<5 \cdot 4 .^{\prime}$ Gastric juice is rich in pepsin a potent proteolytic enzyme which digests thrombus and fibrin. ${ }^{23}$ Furthermore, the highly vascular and motile nature of the upper GIT is likely to promote haemorrhage and inhibit haemostasis. After simulated intraduodenal haemorrhage the three of these factors studied were all altered in a way that would facilitate haemostasis. In clinical terms the $160 \mathrm{ml}$ of blood infused in our study represents a very minor bleed and the changes seen may be more marked after larger bleeds. In a single large clinical study by Chandler and Watkinson in 1953 a temporary achlorhydria was noted in patients with intraduodenal haemorrhage which was not the result of blood reflux but was thought to represent a temporary inhibition of parietal cell function. ${ }^{1}$

The mechanism by which intraluminal blood inhibits acid secretion and gastric motility is unclear. The increase in circulating GIP concentrations may be relevant. Gastric inhibitory peptide is a polypeptide located primarily in the duodenum and jejunum $^{12}$ and its primary role appears to be in glucose metabolism. ${ }^{13}$ It has been shown, however, to inhibit gastric acid secretion and gastric motility in dogs ${ }^{14}$ although these effects remain controversial in man. ${ }^{15}$

Medical therapy of acute upper GI haemorrhage has mainly been directed at inhibiting acid and pepsin secretion or reducing gastroduodenal blood flow. These therapeutic regimes have been applied without a clear understanding of the physiological changes accompanying upper GI haemorrhage. A clearer understanding of these changes may lead to new and more rational approaches to therapy.

Our thanks to Mr John Hearns and laboratory staff for performing the gastric secretory analysis. We are also grateful to Professor Buchanan's laboratory staff for carrying out the GI hormone analysis.

\section{References}

1 Green WF, Kaplan MM, Curtis LE, Levine PH. Effect of acid and pepsin on blood coagulation and platelet aggregation. Gastroenterology 1978; 74: 38-43.

2 Berstad A. Management of acute upper gastrointestinal bleeding. Scand J Gastroenterol 1982; 17 [Suppl 75]: 103-8.

3 Low J, Dodds AJ, Biggs JC. Fibrinolytic activity of gastroduodenal secretions - a possible role in upper gastrointestinal haemorrhage. Thromb Res 1980; 17: 819-30.

4 Hobsley M, Silen W. Use of an insert marker (phenol red) to improve accuracy in gastric secretion studies. Gut 1969; 10: 787-95.

5 McCloy RF. In: Baron JH, ed. Clinical tests of gastric secretion. London: MacMillan Press Limited, 1978: 212-7.

6 Crawford G, Hobsley M. Spectrophotometric estimation of phenol red in gastric juice in the presence of blood. Biochem J 1968; 107: 26-34.

7 George JD. New clinical method for measuring the rate of gastric emptying: the double sampling test meal. Gut 1968; 9: $239-42$.

8 Piper DW. The estimation of peptic activity in gastric juice using radio-iodinated serum albumin as substrate. Gastroenterology 1960; 38: 616-21.

9 Rune SJ. Problems associated with in situ measurement of duodenal pH. In: Domschke W, Wormsley KG, eds. Magen und magenkrankheiten. Stuttgart: Georg Thieme Verlag, 1981: 150-61.

10 Hannibal S, Rune SJ. Duodenal bulb pH in normal subjects. Eur J Clin Invest 1983; 13: 455-60.

11 Chandler GN, Watkinson G. Gastric aspiration in haematemesis. Lancet 1953; ii: 1170-5.

12 Polak JM, Bloom SR, Kuzio M, Brown JC, Pearse AGE. Cellular localisation of gastric inhibitory peptide in the duodenum and jejunum. Gut 1973; 14: 284-8.

13 Andersen DK, Elahi D, Brown JC, Tobin JD, Andres R. Oral glucose augmentation of insulin secretion. Interactions of gastric inhibitory polypeptide with ambient glucose and insulin levels. J Clin Invest 1978; 62: 152-61.

14 Pederson RA, Brown JC. The inhibition of histamine, pentagastrin - and insulin - stimulated canine gastric secretion by pure 'gastric inhibitory polypeptide'. Gastroenterology 1972; 62: 393-400.

15 Maxwell V, Shulkes A, Brown JC, Solomon TE, Walsh JH, Grossman MI. Effect of gastric inhibitory polypeptide on pentagastrin-stimulated acid secretion in man. Dig Dis Sci 1980; 24: 113-6. 